\title{
Modulation of Neutrophil Influx in Glomerulonephritis in the Rat with Anti-Macrophage Inflammatory Protein-2 (MIP-2) Antibody
}

\author{
Lili Feng, Yiyang Xia, Teizo Yoshimura, ${ }^{\star}$ and Curtis B. Wilson \\ Department of Immunology, The Scripps Research Institute, La Jolla, California 92037; and *Immunopathology Section, Laboratory \\ of Immunobiology, National Cancer Institute, Frederick Cancer Research \& Development Center, Frederick, Maryland 21702
}

\begin{abstract}
The role of the chemokine, macrophage inflammatory protein-2 (MIP-2), during anti-glomerular basement membrane (GBM) antibody (Ab) glomerulonephritis (GN) was studied. Rat MIP-2 cDNA had been cloned previously. Recombinant rat MIP-2 ( $r$ MIP-2) from Escherichia coli exhibited neutrophil chemotactic activity and produced neutrophil influx when injected into the rat bladder wall. By using a riboprobe derived from the cDNA and an anti-rMIP-2 polyclonal Ab, MIP-2 was found to be induced in glomeruli with anti-GBM Ab GN as mRNA by 30 min and protein by $4 \mathrm{~h}$, with both disappearing by $24 \mathrm{~h}$. The expression of MIP2 correlated with glomerular neutrophil influx. A single dose of the anti-MIP-2 Ab 30 min before anti-GBM Ab was effective in reducing neutrophil influx $(40 \%$ at $4 \mathrm{~h}, P$ $<0.01$ ) and periodic acid-Schiff deposits containing fibrin (54\% at $24 \mathrm{~h}, P<0.01$ ). The anti-rMIP-2 Ab had no effect on anti-GBM Ab binding (paired-label isotope study). Functional improvement in the glomerular damage was evidenced by a reduction of abnormal proteinuria $(P<0.05)$. These results suggest that MIP-2 is a major neutrophil chemoattractant contributing to influx of neutrophils in Abinduced glomerular inflammation in the rat. (J. Clin. Invest. 1995. 95:1009-1017.) Key words: macrophage inflammatory protein-2 - anti-glomerular basement membrane glomerulonephritis • anti-macrophage inflammatory protein2 antibody $\cdot$ neutrophils $\cdot$ chemokine
\end{abstract}

\section{Introduction}

Neutrophil migration from blood into tissue depends on a cascade of events including chemoattractant activation and selectins and integrin-related adhesion of cells to the endothelium $(1-6)$. Numerous chemoattractants are involved in this process including leukotrienes, complement components, and the recently described chemokine superfamily. This superfamily of basic, heparin-binding molecules of molecular mass $8-10 \mathrm{kD}$ with chemotactic and inflammatory properties has been termed intercrines, small cytokines, and recently by the recommended nomenclature, chemokines (7). The superfamily is characterized by four conserved cysteines with two disulfide bridges and

Address correspondence to Curtis B. Wilson, MD, Department of Immunology (IMM5), The Scripps Research Institute, 10666 North Torrey Pines Road, La Jolla, CA 92037. Phone: 619-554-8056; FAX: 619-5546705.

Received for publication 5 July 1994 and in revised form 26 October 1994.

The Journal of Clinical Investigation, Inc.

Volume 95, March 1995, 1009-1017 is subdivided into the $\alpha$ subfamily, in which the first two cysteines are separated by another amino acid (C-X-C), and the $\beta$ subfamily, in which the cysteines are adjacent (C-C) (for reviews see references 8 and 9 ). The $\alpha$ subfamily includes platelet factor-4 (PF-4), interleukin-8 (IL-8/NAP-1), GRO/ MGSA, cytokine-induced neutrophil chemoattractant (CINC) $1 /$ $\mathrm{KC}$, and macrophage inflammatory protein-2 (MIP-2), which are neutrophil chemoattractants and activators. The $\beta$ subfamily includes RANTES, MIP-1, and monocyte chemotactic protein1 (MCP-1)/JE. The two subfamilies represent two gene clusters on two different chromosomes.

In the rat, IL-8, a major neutrophil chemoattractant in humans, has not been identified with certainty, and CINC/KC and MIP-2 may provide this function. These two chemokines are presumed to be homologues of the human GRO $\alpha, \beta$, and $\gamma$ genes $(10-13)$. CINC/KC was isolated from the rat kidney epithelioid cell line NRK-52E and has been cloned $(14,15)$. Previous studies in the mouse showed that anti-MIP-2 antibody (Ab) delayed, but did not prevent, inflammation produced by intracisternal challenge of pneumococci (16); however, it did reduce by $\sim 40 \%$ the influx of neutrophils in a model of $M y c o-$ bacterium bovis bacilli Calmette-Guérin (BCG)-induced peritonitis (17). Pulmonary instillation of lipopolysaccharide (LPS) in rats produced a rapid and marked increase in MIP-2 and $\mathrm{KC}$ levels (18), and a marked induction of both $\mathrm{KC}$ and MIP-2 was observed in the alveolar macrophages of hamsters after injection of opsonized particles (19).

To determine the role of MIP-2 in inflammatory glomerular injury, we used a rat MIP- 2 cDNA recovered previously during cloning of rat gro/KC and expressed recombinant MIP-2 ( $r$ MIP-2). The $r$ MIP-2 attracted neutrophils in a chemotaxis assay and produced neutrophil influx when injected into the rat bladder wall; the $r$ MIP-2 also was able to attract neutrophil influx into rat lung by intratracheal instillation (Rose, C. E., personal communication). We then evaluated the protective effects of a polyclonal $\mathrm{Ab}$ raised to rat $r$ MIP-2 in experimental anti-glomerular basement membrane (GBM) Ab-induced glomerulonephritis (GN).

\section{Methods}

Construction of a cDNA library, screening, and DNA sequencing Spleen cells obtained from Fisher rats were incubated with $5 \mu \mathrm{g} / \mathrm{ml}$ of Con A for $4 \mathrm{~h}$, poly (A) RNA was isolated, and cDNA synthesized by

1. Abbreviations used in this paper: CINC, cytokine-induced neutrophil chemoattractant; GAP, riboprobe for GAPDH; GAPDH, glyceraldehyde-3-phosphate dehydrogenase; GBM, glomerular basement membrane; GN, glomerulonephritis; ICAM-1, intercellular adhesion molecule-1; MCP, monocyte chemotactic protein; MIP, macrophage inflammatory protein; NRS, normal rabbit serum; $r$ MIP-2, recombinant MIP-2. 
a modification of the Gubler and Hoffman method (20) was used to prepare a library in $\lambda$ ZAP II vector.

Oligodeoxynucleotide probes were prepared from a portion of human GRO cDNA sequence, where a highly conserved sequence was expected based on the similarity between human and mouse GRO (10). The sequence of the probe was 5'-dGTG GCT ATG ATC TCG GTT TGG GTG CAG TGG-3'. Approximately $5 \times 10^{5}$ recombinant phages from the cDNA library were screened by high-density plaque hybridization with the ${ }^{32} \mathrm{P}$-labeled oligonucleotide probe. Phagemids carried within $\lambda$ ZAP II recombinants were rescued with helper phage (21). cDNA inserts were sequenced by the dideoxynucleoside triphosphate chain termination method (22).

Expression of rat MIP-2 in Escherichia coli. DNA encoding MIP2 without signal peptide was PCR-amplified and subcloned into pETM1 (23). pET-M1 was modified from pET-11a with a sequence coding for $6 \times$ histidine residues $(6 \times$ His $)$ for ease in purification $(23,24)$. The host strain, BL21 (DE3), was transformed by pETMIP-2 and was cultured in LB broth with ampicillin $(100 \mu \mathrm{g} / \mathrm{ml})$ and induced with 0.5 $\mathrm{mM}$ of isopropyl- $\beta$-thiogalactopyranoside at $37^{\circ} \mathrm{C}$ for $4 \mathrm{~h}$. The cell culture was centrifuged at $5,000 \mathrm{~g}$ for $10 \mathrm{~min}$, and the pellet was stored at $-20^{\circ} \mathrm{C}$ for subsequent purification.

An Ni-NTA affinity resin for binding the $6 \times$ His tag was purchased from Invitrogen (San Diego, CA). The purification procedure of the manufacturer was used with some modifications, as described previously (24).

Purification and refolding of $r M I P-2$ and Ab production. The purified, denatured, and insoluble $r$ MIP-2 was dialyzed against reduction buffer ( $100 \mathrm{mM}$ Tris- $\mathrm{HCl}[\mathrm{pH} \mathrm{7.5]}$ and $4 \mathrm{M}$ urea) at the concentration of $1 \mathrm{mg} / \mathrm{ml}$. To reduce the concentration of the denaturing reagents and to initiate refolding, this mixture was diluted at $4^{\circ} \mathrm{C}$ with dilution buffer ( $100 \mathrm{mM}$ Tris- $\mathrm{HCl}$ [pH 8.0], $100 \mathrm{mM} \mathrm{NaCl}, 5 \mathrm{mM} \mathrm{CaCl}_{2}$ and $0.01 \%$ Triton X-100) to a final concentration of $0.1 \mathrm{M}$ urea. The dilution step was performed by adding $10 \mathrm{ml} / \mathrm{h}$ dilution buffer while gently stirring, thus allowing reshuffling of the mismatched disulfide bonds. After refolding, buffer was exchanged to $0.9 \% \mathrm{NaCl}$ by dialysis.

A polyclonal antiserum was raised by immunizing a rabbit with $r$ MIP-2. An initial dose of $1 \mathrm{mg}$ of $r$ MIP-2 with complete Freund's adjuvant was injected subcutaneously. Subsequent doses of $0.5 \mathrm{mg}$ in incomplete Freund's adjuvant were given weekly.

Assessment of neutrophil chemotaxis. Rat peritoneal neutrophils were prepared by injection of $5 \mathrm{ml}$ of $0.2 \%$ sodium caseinate in phosphate-buffered saline into the peritoneal cavities of Fisher rats (25). The neutrophil chemotaxis assay was performed with a $10-\mu \mathrm{M}$-thick polyvinylpyrrolidone-free $3-\mu \mathrm{M}$ pore size polycarbonate filter (26). The number of neutrophils per well (in triplicate) was $5 \times 10^{4}$. After 40 min at $37^{\circ} \mathrm{C}$ in humidified air with $5 \% \mathrm{CO}_{2}$, filters were removed. Cells that did not migrate were wiped away; the filters were air dried and stained with Diff-Quik (American Scientific Products, McGaw Park, IL). Migrated cells were counted microscopically at a magnification of 400. HBSS was the negative control. The experiment has been repeated three times.

To assess in vivo chemotactic activity, either $50 \mu \mathrm{l}$ of a $r$ MIP-2 solution $(200 \mu \mathrm{g} / \mathrm{ml})$ or phosphate-buffered saline was injected into the bladder wall of anesthetized Lewis rats under direct vision using a 30gauge needle. The bladders were obtained for histologic evaluation $2 \mathrm{~h}$ later.

Transfection of rat MIP-2 into COS-7. The full-length rat MIP-2 was subcloned into pCDM8 (Invitrogen) to generate pCDM8MIP-2. pCDM8MIP-2 was transfected into subconfluent COS-7 by electroporation of $8 \times 10^{6} / \mathrm{ml}$ cells at $1,500 \mathrm{~V}, 1,000 \mu \mathrm{F}$. The antisense clone in the same vector was used for mock transfection as a control. After 48 $h$ of incubation with serum-free medium, the supernatant was collected for chemoattractant assay and immunoblot. The cell pellet was used for RNA extraction.

Anti-GBM $A b G N$. Anti-GBM Ab-induced GN was produced as previously published using a rabbit anti-rat GBM Ab that had been decomplemented and absorbed with rat peripheral blood cells (27). Four groups of six rats each were given either $0.5 \mathrm{ml}$ of anti-MIP-
$2 \mathrm{Ab}$ or normal rabbit serum (NRS) intravenously $30 \mathrm{~min}$ prior to administration of anti-GBM Ab or normal rabbit serum (NRS). Control and anti-MIP-2 Ab groups $(n=6)$ were examined at 4 or $24 \mathrm{~h}$ for glomerular neutrophil influx and 24-h proteinuria. To assess the effects of the anti-MIP-2 Ab on binding of anti-GBM Ab, a paired label isotopic binding assay was done as described previously (28).

Probe preparation, glomerular RNA isolation, and RNase protection assay. For antisense riboprobe synthesis, the rat MIP-2 (1-174) was used for in vitro transcription. cDNAs of rat TNF $\alpha$ (818-1144; GenBank accession No. L00981) and IL-1 $\beta$ (450-667; GenBank accession No. M98820) were used for preparation of riboprobes. Rat intercellular adhesion molecule-1 (ICAM-1) (24) was described previously (29, 30). Glomeruli were isolated as before (29). After washing with $0.9 \%$ saline, the glomeruli were homogenized in $4 \mathrm{M}$ guanidine isothiocyante with a sonicator (Heat Systems-Ultrasonics, Plainview, NY). The RNA was prepared by a single-step method (31). For study, $5 \mu \mathrm{g}$ of glomerular total RNA was hybridized with $1 \times 10^{5} \mathrm{cpm}$ of each $\left[\alpha^{32} \mathrm{P}\right]$ rat antisense riboprobes for MIP-2, ICAM-1, TNF $\alpha$, IL- $1 \beta$, and glyceraldehyde-3-phosphate dehydrogenase (GAP), which has been described previously (24). The RNase protection assay was described previously (24), with the protected bands quantitated by a radioanalytic imaging system (AMBIS Systems, San Diego, CA). The data are presented as a ratio of the counts per minute for specific mRNA/GAPDH mRNA bands to ensure a constant quantity of RNA in each sample.

Western blot. The level of MIP-2 was analyzed by Western blot analysis as described previously $(26,32)$. In brief, glomeruli from the three rats at each time point were pooled per preparation. The glomeruli were homogenized in phosphate-buffered saline with protease inhibitors. After centrifugation, the supernatant was collected. The supernatant was incubated with protein A-Sepharose 4B (Pharmacia LKB Biotechnology Inc., Piscataway, NJ) for $1 \mathrm{~h}$ to remove rabbit Ig. After centrifugation, the supernatant was quantitated for protein content by the Bradford assay, $100 \mu \mathrm{g}$ of each sample was electrophoresed on SDS-polyacrylamide gel and transferred onto nitrocellulose (Schleicher \& Schuell, Inc., Keene, NH). The supernatant from transfectants was used directly for loading without further treatment. The blot was incubated in the Ab solution (diluted 1:250) overnight and was treated with goat anti-rabbit IgG conjugated with alkaline phosphatase (diluted 1:1,500).

Morphologic study. At time of killing, renal tissue samples were fixed in $10 \%$ formalin for light microscopy or were snap-frozen in liquid nitrogen with Tissue-Tek (Miles, Inc., Elkhart, IN) for immunofluorescence microscopy. Histologic examination was performed on paraffin sections $(2-3 \mu \mathrm{m})$ stained with periodic acid-Schiff reaction and hematoxylin counterstain. Glomerular neutrophil influx was determined by counting neutrophils in 35 paraffin-embedded glomerular cross-sections of kidney stained with periodic acid-Schiff (27). All morphologic and functional data are presented as mean \pm SE. Statistical analysis was done using the Mann-Whitney test.

In situ hybridization. In situ hybridization was performed as described previously with some modification (33). Briefly, kidneys were perfused and prefixed with $4 \%$ paraformaldehyde. The tissues were embedded in OCT (Miles, Inc.) and then frozen on dry ice. ${ }^{35} \mathrm{~S}$-Labeled antisense and sense riboprobes were transcribed from both directions using MIP-2 cDNA cloned in pBluescript. Frozen sections (4-6 $\mu \mathrm{m}$ thick) were fixed in $4 \%$ paraformaldehyde for $10 \mathrm{~min}$ on ice and deproteinated in proteinase $\mathrm{K}$ solution $(1 \mu \mathrm{g} / \mathrm{ml})$ for $10 \mathrm{~min}$ at room temperature. After washing in $0.5 \times \mathrm{SSC}$ for $10 \mathrm{~min}$, prehybridization was performed at $42^{\circ} \mathrm{C}$ for $2 \mathrm{~h}$ in $50 \mu \mathrm{l}$ of prehybridization buffer per section. Prehybridization buffer contained $10 \mathrm{mM}$ DTT, $0.3 \mathrm{M} \mathrm{NaCl}, 20 \mathrm{mM}$ Tris $(\mathrm{pH} \mathrm{8.0)}, 5 \mathrm{mM}$ EDTA, $1 \times$ Denhardt's, $10 \%$ dextran sulfate, $50 \%$ formamide. $10 \mu \mathrm{l}$ of hybridization buffer with radiolabeled probe $\left(3 \times 10^{5} \mathrm{cpm}\right.$ per section) was added directly into the bubble of prehybridization buffer covering the sections. Hybridization was performed at $55^{\circ} \mathrm{C}$ overnight. After washing in $2 \times \mathrm{SSC}$, slides were immersed in RNase digestion buffer ( $20 \mu \mathrm{g} / \mathrm{ml}$ RNase A) at room temperature for $30 \mathrm{~min}$. The slides were then washed sequentially in $2 \times$ SSC with $2 \mathrm{mM}$ EDTA, $0.1 \times$ SSC with $1 \mathrm{mM}$ EDTA, and $10 \mathrm{mM} \beta$-mercaptoethanol at $50^{\circ} \mathrm{C}$ for $2 \mathrm{~h}$. The slides were finally washed in $0.5 \times$ SSC without 
-25 TCCAACCACTCTTTGGTCCAGAGCC -1

ATG GCC CCT CCC ACT CGC CAG CTC CTC AAT GCT GTA CTG GTC CTG CTC 48 MET Ala Pro Pro Thr Arg Gln Leu Leu Asn Ala Val Leu Val Leu Leu 16 CTC CTG CTG GCC ACC AAC CAT CAG GGT ACA GGG GTT GTT GTG GCC AGT 96 Leu Leu Leu Ala Thr Asn His Gln Gly Thr Gly Val val Val Ala Ser 32 GAG CTG CGC TGT CAA TGC CTG ACG ACC CTA CCA AGG GTT GAC TTC AAG 144 Glu Leu Arg Gre Gin Cys Leu Thr Thr Leu Pro Arg val Asp phe Lys 48 AAC ATC CAG AGC TTG ACG GTG ACC CCT CCA GGA CCC CAC TGC GCC CAG 192 Asn Ile Gln Ser Leu Thr Val Thr Pro Pro Gly Pro His a Ala Gln 64 ACA GAA GTC ATA GCC ACT CTT AAG GAT GGT CAT GAA GTT TGT CTC AAC 240 Thr Glu Val Ile Ala Thr Leu Lys Asp Gly His Glu Val Leu Asn 80 CCT GAA GCC CCC TTG GTT CAG AGG ATC GTC CAA AAG ATA CTG AAC AMA 288 Pro Glu Ala Pro Leu val Gln Arg Ile Val Gln Lys Ile Leu Asn Lys 96 GGC AAG GCT AAC TGA CCTGGGAGGAAGACATGGGCTCCTGTACCC Gly Lys Ala Asn END

Figure 1. The nucleotide (upper case) and deduced amino acid (lower case) sequences of rat MIP-2 are shown. The cleavage site of the signal peptide is marked with an asterisk. The conserved cysteines are shadowed.

EDTA and $\beta$-mercaptoethanol for 10 min twice. After dehydration, the slides were dried. After autoradiography for $3 \mathrm{~d}$, the slides were dipped in Kodak NTB2 nuclear emulsion diluted in $1: 1$ with water at $42^{\circ} \mathrm{C}$. Exposure was done at $4^{\circ} \mathrm{C}$ in the dark for $4 \mathrm{wk}$ before development.

\section{Results}

Cloning of rat MIP-2. About $5 \times 10^{5}$ phages were initially screened with the gro oligonucleotide probe shown in Methods. After two rounds of screening and DNA sequencing from denatured plasmids, it was found that one clone encoded for rat MIP-2 (Fig. 1). Rat MIP-2 cDNA had 1,008 bp with an open reading frame of $300 \mathrm{bp}$, which encodes for a 100-amino acid protein. The cDNA clone did not contain a poly (A) tail. The sequence was identical to a partial rat MIP-2 cDNA published by Huang et al. (18). The deduced amino acid sequence of rat MIP-2 was highly similar to that of mouse MIP-2 (10). As reported by Tekamp-Olson et al. (10), human homologues of mouse MIP-2 are identical to human GRO $\beta$ and GRO $\gamma$. In the $3^{\prime}$ untranslated region, there were 10 copies of AU-rich motifs, which are involved in the regulation of mRNA stability (34).

E. coli expression of rMIP-2 and chemotactic assay in vitro and in vivo. The $r$ MIP-2 was expressed as a fusion protein with a $6 \times$ His tag at the amino termini in BL21 (DE3) under the control of $T_{7}$ RNA polymerase. The expected molecular mass of the MIP-2 peptide (amino acids $29-100$ ) is $8 \mathrm{kD}$; the molecular mass of the peptide coded by polylinker region and $6 \times$ His is $0.3 \mathrm{kD}$. The size of the total molecule is $\sim 8.3 \mathrm{kD}$. Fig. 2 is a Western blot which shows the two forms of MIP-2 expressed in COS-7 (lane 3) and in E. coli (lane 4) that reacted with the $\mathrm{Ab}$ generated against the $r$ MIP-2. The higher molecular weight of the $E$. coli form (lane 4 ) is due to the extra amino acids fused with MIP-2 during expression. The $r$ MIP-2 expressed in $E$. coli was purified and showed chemotactic activity detected as the number of cells that migrated through the filter, with the activity shown at the dose of $40 \mathrm{ng} / \mathrm{ml}$, while the peak was at the dose of $1 \mu \mathrm{g} / \mathrm{ml}$. Fig. 3 shows the chemotactic activity of rat $r$ MIP-2 versus rat peritoneal neutrophils. Margination and extravasation of neutrophils was induced mainly in and around venules in the lamina propria of the rat bladder $2 \mathrm{~h}$ after administration of $r$ MIP-2 as shown in Fig. 4. Intratracheal instillation of $r$ MIP-2 caused a dramatic increase in neutrophil influx (Rose, C. E., personal communication).

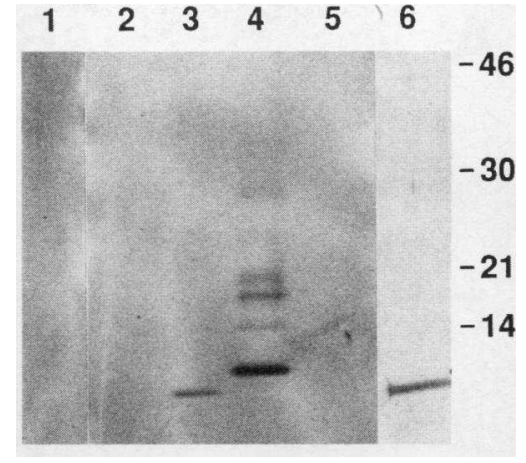

Figure 2. The specificity of the anti-MIP-2 Ab and expression of MIP-2 recombinant protein, purification by Ni-NTA affinity resin, and immunoblot of KC polypeptide are shown as described in Methods. Preimmune serum showed no reactivity (lane 1 ) with $20 \mu \mathrm{l}$ of the supernatant from COS-7 transfected with sense MIP-2 in pCDM8. No reaction was seen (lane 2) with $20 \mu \mathrm{l}$ of supernatant from COS-7 transfected with antisense MIP-2 in PCDM8 when reacted with the antiMIP-2 Ab. In lane 3, the anti-MIP-2 Ab reacted with the same supernatant from the sense MIP-2 transfected COS-7 used in lane 1. In lane 4, the $r$ MIP-2 expressed in $E$. coli reacted with the anti-MIP-2 Ab. In lane 5, the anti-MIP-2 Ab had no reactivity with the serum-free supernatant of a KC transfectant, whereas this KC-containing supernatant was reactive with anti-KC antibody, as shown in lane 6 . Numbers on the right are kilodaltons.

Specificity of anti-rMIP-2 $A b$. The antiserum generated against $r$ MIP-2 reacted monospecifically against supernatant from COS-7 transfectants with rat MIP-2, pCDM8MIP-2, but did not recognize any proteins in supernatants from antisense transfectants in the same plasmid (Fig. 2, lane 2). Preimmune serum also showed no reactivity (Fig. 2, lane 1 ). In particular, antiserum to MIP-2 did not cross-react with the serum-free supernatant from KC transfectants (lane 5), while anti-KC did react (lane 6).

Expression of MIP-2 in the glomeruli by RNase protection assay and in situ hybridization. mRNA expression of MIP-2 in glomeruli was as early as $30 \mathrm{~min}$ after $\mathrm{Ab}$ injection (data not shown). As shown in Fig. 5, at the 4-h time point the mRNA

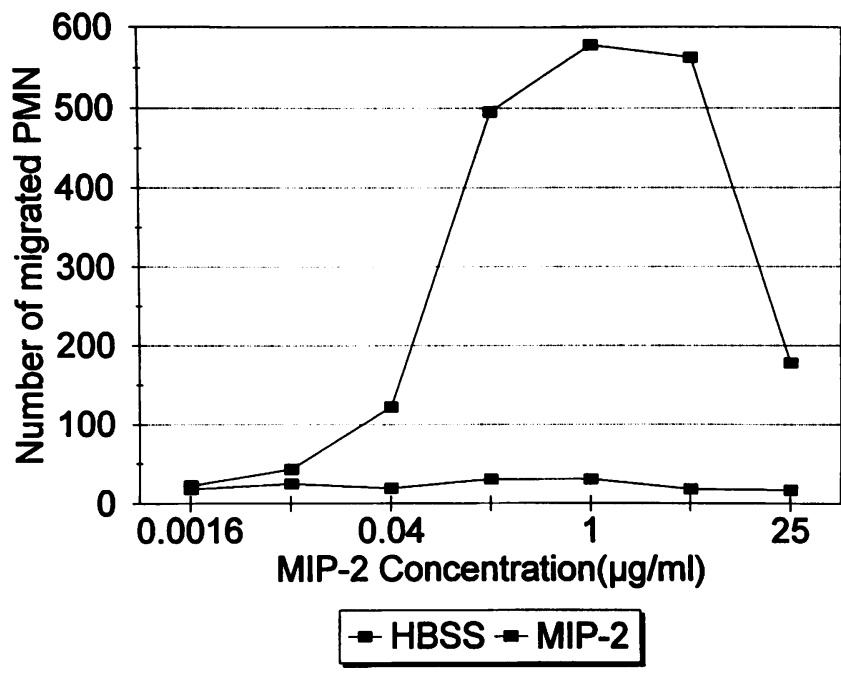

Figure 3. The in vitro chemotactic activity of the $r$ MIP-2 is shown for one study which is representative of three done. The data are presented as the mean of triplicate wells for the numbers of PMNs that migrated toward the increasing concentrations of $r$ MIP- 2 in comparison with a HBSS with $0.2 \%$ BSA as a negative control. The triplicate wells were in close agreement. 

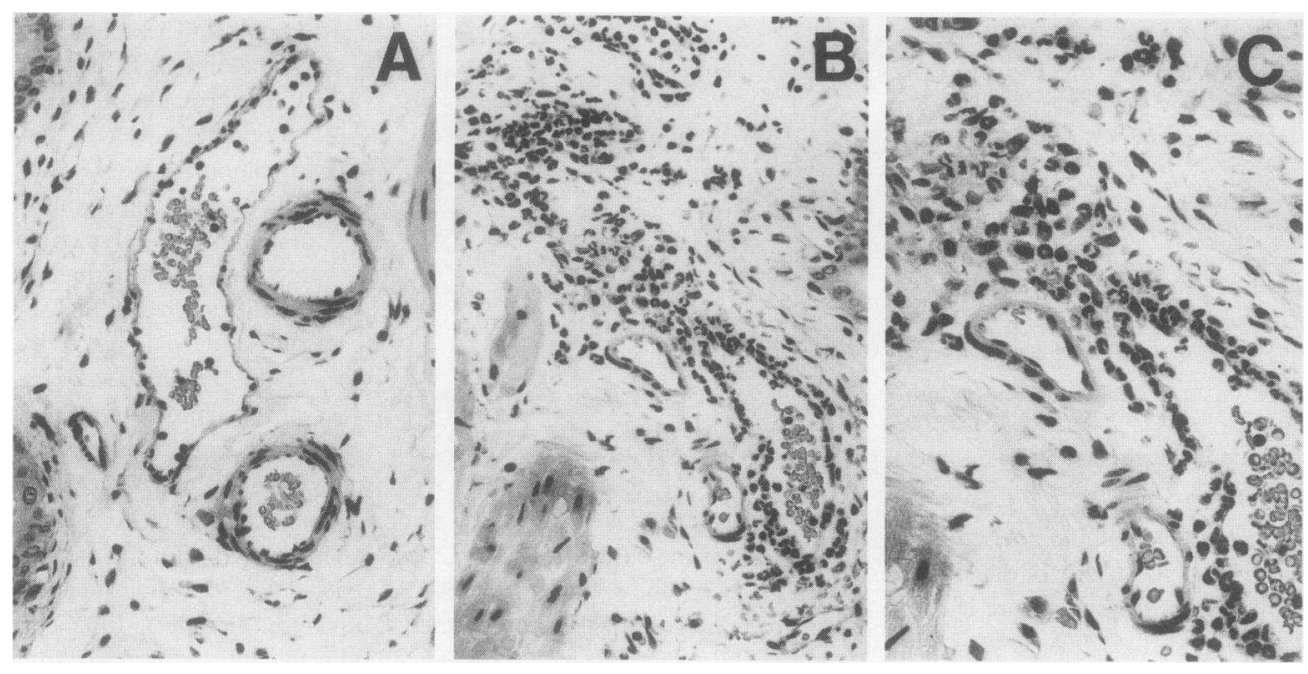

Figure 4. The injection of the bladder wall with saline $(A)$ caused no influx in neutrophils in contrast to $r$ MIP-2, which caused margination and extravasation of neutrophils in and around the small venules at low and high power $(B$ and $C)$. level was still positive, which correlated well with the neutrophil infiltration; at $24 \mathrm{~h}$, it declined to the level not detectable. Interestingly, treatment with anti-MIP-2 Ab affected the mRNA level of MIP-2. At $4 \mathrm{~h}$, the MIP-2 mRNA level of the group II (anti-GBM Ab and $0.5 \mathrm{ml}$ of anti-MIP-2) was $\sim 1.35 \pm 0.493$, as scanned by AMBIS and factored relatively by GAP, significantly lower than $2.675 \pm 0.532(P<0.05)$, the level of group I (anti-GBM Ab and $0.5 \mathrm{ml}$ of NRS). The attenuation of inflammatory infiltrates by the anti-MIP-2 Ab might account for this reduction. MIP-2 protein expressed in the glomeruli was detected by Western blot (Fig. 5). MIP-2 protein expression correlated with the mRNA level expressed at $4 \mathrm{~h}$ and declined at $24 \mathrm{~h}$. There was no marked difference of protein level between group I and group II as shown at mRNA level (Fig. 6), perhaps due to the difference of the sensitivity between two methods.

In situ hybridization demonstrated that the MIP-2 mRNA was confined to the glomeruli $4 \mathrm{~h}$ after anti-GBM Ab administration (Fig. 7). The individual cells responsible for the mRNA included mesangial cells and intraluminal inflammatory cells.

mRNA expression of ICAM-1,IL-1 $\beta$, and TNF $\alpha$ in the glomeruli. The time course of mRNA expression of ICAM-1, IL$1 \beta$, and TNF $\alpha$ during GN was similar to that found before
$(29,30)$. Anti-MIP-2 Ab treatment did not change the mRNA expression levels of these three genes according to AMBISscanned and quantitated data which were factored relative to the GAPDH mRNA levels as shown in Fig. 8. These findings suggest that the anti-MIP-2 Ab did not have any overall effect on the underlying inflammatory mediator stimulus for the generation of the anti-GBM Ab-induced lesion.

Histology. The glomerular histologic features were those of a severe infiltrative/proliferative GN with large numbers of infiltrating neutrophils at $4 \mathrm{~h}$ (Fig. $9 \mathrm{~A}$ ), which largely disappeared by $24 \mathrm{~h}$. The mean of $608 \pm 26$ neutrophils $(n=6)$ per 35 glomeruli (17.4 neutrophils/glomerulus) in the NRS control group was reduced by $\sim 40 \%$ to $362 \pm 6(n=6)$ ( 10.4 neutrophils/glomerulus) with anti-MIP-2 $\mathrm{Ab}$ administration ( $P$ $<0.01$ ) (Fig. $9 \mathrm{~B}$ ). The anti-MIP-2 Ab had its greatest effect in reducing infiltration of high numbers of neutrophils, so that only $18.1 \%$ of glomeruli had 15 or more neutrophils per glomerulus after anti-MIP-2 Ab treatment compared with $64.7 \%$ in the NRS control group. By $24 \mathrm{~h}$ the neutrophils had largely disappeared, as is the usual finding in this model, with $54 \pm 3$ compared with $35 \pm 2$ per 35 glomeruli $(P<0.01)$ ( 1.5 vs 1.0 per glomerulus) in the NRS control and anti-MIP-2 Ab groups ( $n=6$ each $)$, respectively. Mononuclear infiltrative cells were

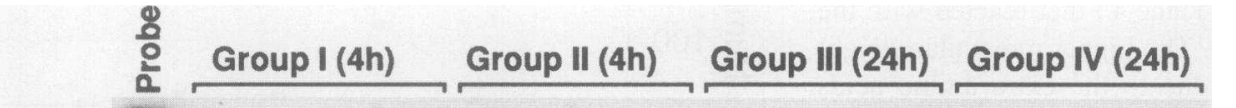

MIP-2 1

GAP
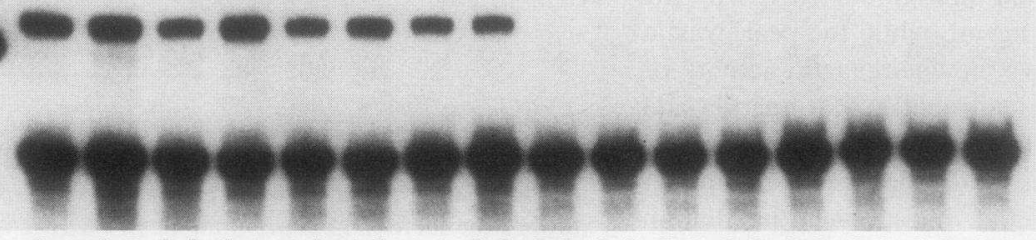

$\frac{\text { MIP-2 cpm }}{\text { GAP cpm }} \times 10$
Figure 5. Expression of MIP-2 mRNA analyzed by RNase protection assay. $5 \mu \mathrm{g}$ of total RNA was hybridized with riboprobes, as described in Methods. The [ $\alpha{ }^{32} \mathrm{P}$ ] UTP-labeled MIP-2 and GAP riboprobes were protected with the complementary mRNA from glomeruli. The gel was scanned on AMBIS, and the final values were factored relative to the GAPDH mRNA levels. In the RNase protection assay, the protected band is shorter than the probe since the polylinker regions present in the probe are not protected. Groups I and III received NRS; groups II and IV received anti-MIP-2 Ab. 


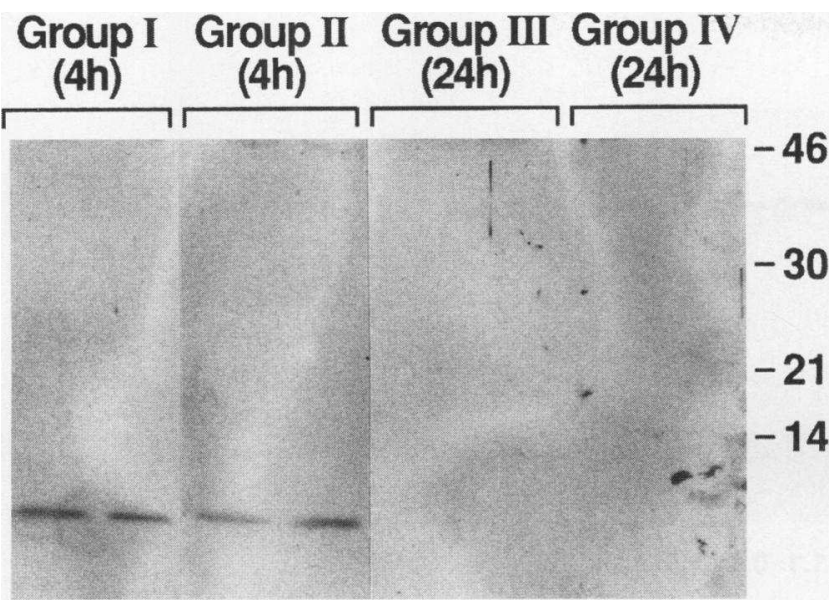

Figure 6. Expression of MIP-2 protein in glomeruli analyzed by Western blot. $100 \mu \mathrm{g}$ of total glomerular lysate from a pool of three rats was loaded.

also present. There was evidence of cell death at $24 \mathrm{~h}$, with scattered nuclear debris. The histologic lesion at $24 \mathrm{~h}$ in the control group had large areas of periodic acid-Schiff-positive material occluding the lumens of glomerular capillaries in a mean of $65 \pm 2 \%$ of the 35 glomeruli per rat evaluated $(n=6)$ (Fig. $9 C$ ). This material corresponded to areas of fibrin deposit detected by immunofluorescence study (29). The amount of this material was reduced by the anti-MIP- $2 \mathrm{Ab}$ administration, so that only a mean of $28 \pm 3 \%$ of glomeruli $(n=6)$ had any of the material detected (Fig. $9 D)(P<0.01)$.

Renal function. Functional changes as monitored by 24- $\mathrm{h}$ protein excretion were also improved after anti-MIP-2 Ab administration. The mean proteinuria of $193 \pm 16 \mathrm{mg} / 24 \mathrm{~h}$ in the NRS group $(n=6)$ decreased to $121 \pm 22 \mathrm{mg} / 24 \mathrm{~h}$ after Ab treatment $(n=6)(P<0.05)$.

Binding of anti-GBM $A b$ and complement fixation. To determine if the beneficial effect of the anti-MIP-2 Ab could have been mediated via an inhibition of binding of the anti-GBM Ab, thereby lessening the immunonephritogenic stimulus, a pairedlabel binding study was done. Of the $100 \mu \mathrm{g}$ of anti-GBM Ab given to groups of rats $(n=3)$ having received either antiMIP-2 or NRS 30 min earlier, an identical mean of $0.381 \mu \mathrm{l}$ $\mathrm{Ab} / \mathrm{g}$ kidney was found bound in the washed renal homogenate at $24 \mathrm{~h}$, indicating no interference with anti-GBM Ab binding. By immunofluorescence, no differences were detected in C3 deposits in the GBM between the groups, suggesting that the anti-MIP-2 Ab had no substantial effect on complement fixation.

\section{Discussion}

Leukocyte accumulation in vessels including the glomerulus is the end result of a cascade of events resulting from immune activation of complement and other chemoattractants including the chemokines, cytokine activation, and engagement of a number of cell adhesion molecules including the selectins and integrins with their counterreceptor molecules (35-41). For example, in the kidney glomerular endothelial cells were used to demonstrate a role for L-selectin in leukocyte binding (42). Adhesion of neutrophils and monocytes/macrophages to human mesangial cells involved ICAM-1 and CD11/CD18 (43). ICAM-1 and vascular cell adhesion molecule- 1 are expressed on glomerular epithelial cells (44). ICAM-1 expression is
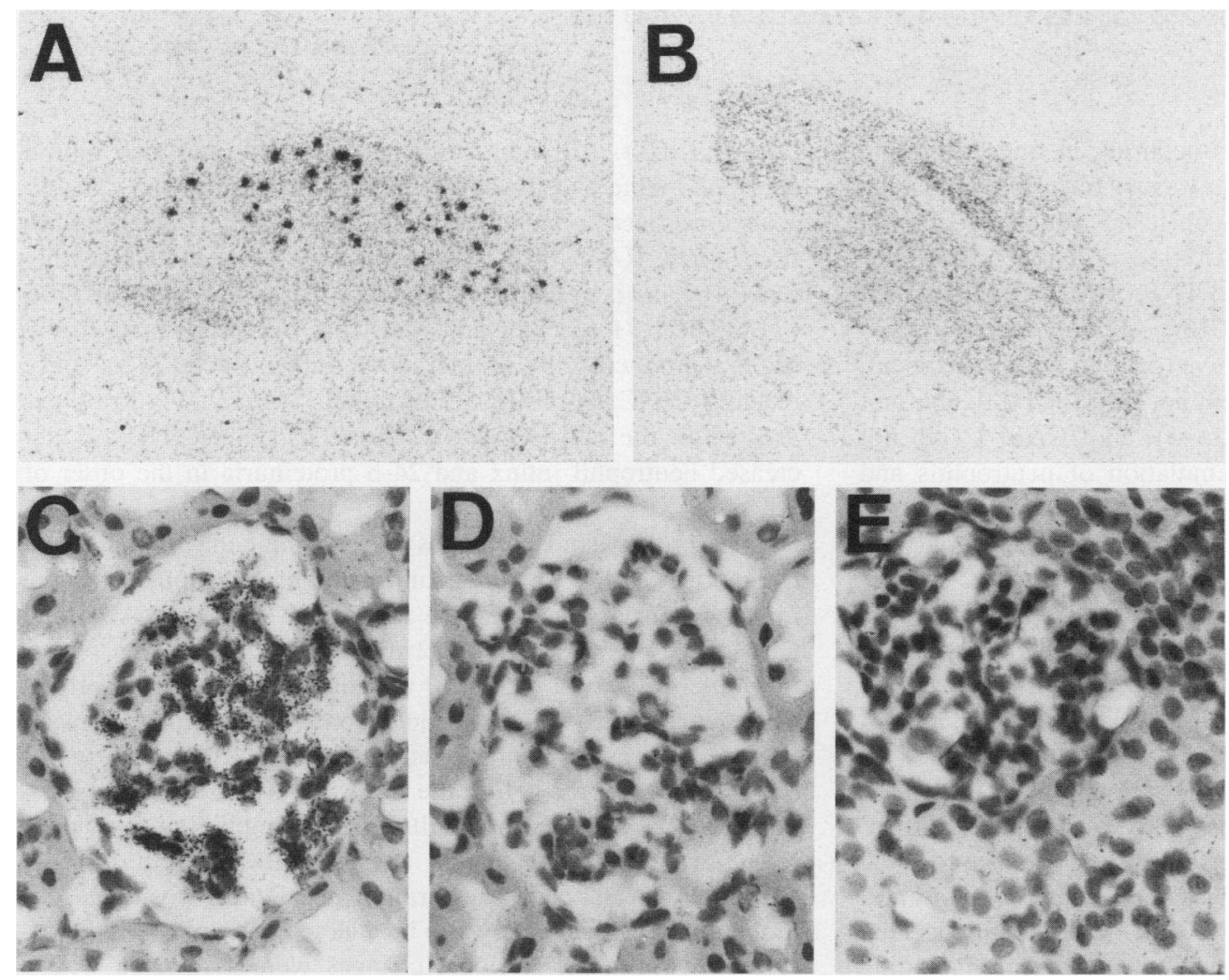

Figure 7. The in situ hybridization results are illustrated. In $A$, an autoradiograph of a section of kidney from a rat receiving anti-GBM $\mathrm{Ab} 4 \mathrm{~h}$ earlier is seen reacted with antisense MIP-2 riboprobe for comparison with the control sense MIP-2 riboprobe shown in $B$. The slides were exposed to $x$-ray film for $3 \mathrm{~d}$ before development. The glomeruli of the kidney in $A$ are strongly positive. In $C$, the reaction of antisense and in $D$ sense MIP-2 riboprobes are shown, respectively, from the stained section used in $A$. In $E$, the lack of reaction of the antisense MIP-2 riboprobe on normal kidney is shown. In $C$, MIP-2 mRNA is detected as black grains in individual glomerular cells which appear to be mesangial and intraluminal. 

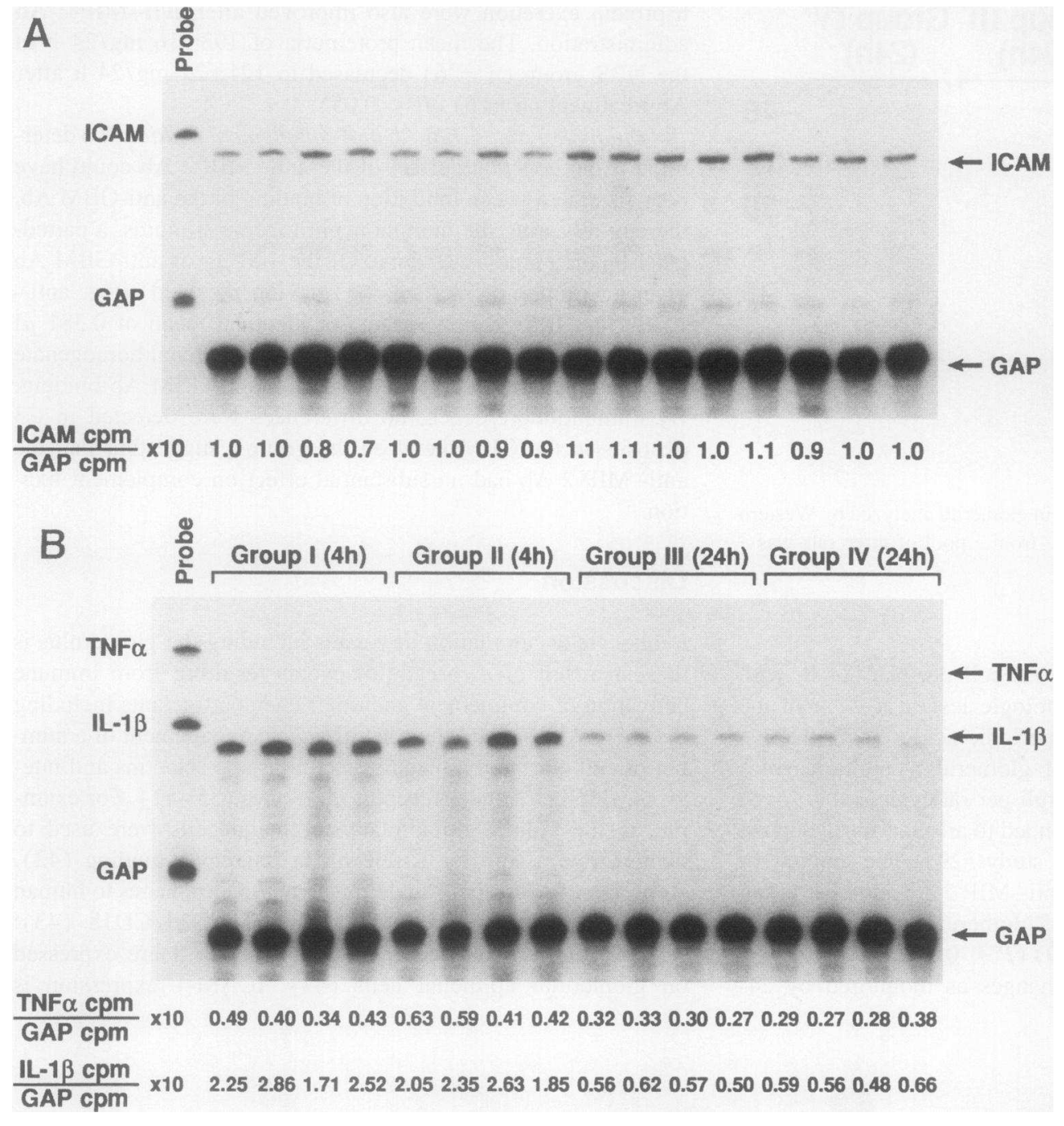

Figure 8. A shows the RNase protection results for ICAM expression in four rats from each of the four groups. No differences are apparent in mRNA expression in comparing the different time points. In $B$, the RNase protection results for TNF $\alpha$ and IL- $1 \beta$ mRNA expression are shown. The very faint TNF $\alpha$ bands were sufficient for AMBIS quantitation, and these as well as the IL- $1 \beta$ bands showed no difference relative to GAPDH (GAP) at the 4and 24-h time points. Groups I and III received NRS; groups II and IV received anti-MIP-2 $\mathrm{Ab}$.

upregulated in autoimmune lupus nephritis in mice (45) and has been reported to be increased in various forms of human GN (46-49). The IL-1 receptor antagonist was found to decrease neutrophil accumulation and ICAM-1 expression in the antiGBM Ab GN model (30). Abs to TNF $\alpha$ or CD18 diminished neutrophil accumulation in anti-GBM Ab GN, whereas antiE-selectin or CD11b were ineffective (50). In this same model, it has been reported that TNF $\alpha$ (but not IL-1), CD11b (but not CD11a), very late antigen-4 (VLA-4), and ICAM-1 (but not E-selectin) are required for accumulation of neutrophils and proteinuria (51). Abs reactive with ICAM-1 or lymphocyte function-associated antigen-1 $\alpha$ (LFA-1 $\alpha$ ) reduced injury in anti-GBM Ab GN in the WKY rat $(52,53)$.

Adhesion involves not only integrin and selectin interactions with their ligands, but also activation signals provided by chemoattractants including the chemokine family (54). For example, C5a- and leukotriene $\mathrm{B}_{4}\left(\mathrm{LTB}_{4}\right)$-induced adhesion of monocytes to human mesangial cells could be partially inhibited by Abs reactive with the common $\beta$ CD18 subunit of CD11/CD18 (55); of interest, anti-selectin Abs ( L, E, or P) had no effect. Members of the chemokine superfamily are being associated with glomerular injury (56). IL-8 has been identified in glomeruli from patients with IgA GN (57). IL-8 can be induced in mesangial cells and renal epithelial cells by cytokines including
IL-1 (58-62). Although a chemokine, IL-8 can also inhibit neutrophil adherence through receptor modulation (63). MCP1 also has been found in mesangial cells $(61,64-68)$, as has IP-10 (69). RANTES has been found in renal tubular epithelium (70) and is upregulated in mouse mesangial cells by TNF $\alpha$ (71). The IL-1 receptor antagonist has been shown to inhibit MCP-1 production by glomerular mesangial cells (72). Very recently CINC/KC mRNA and protein were shown to be expressed in the anti-GBM Ab model, and anti-CINC Ab decreased neutrophil influx and 24-h proteinuria in the order of $50 \%(73)$.

The present study provides data on the contribution of the chemokine, MIP-2, in the accumulation of neutrophils of acute immune injury induced by the fixation of anti-GBM Ab to the GBM. The presence of MIP-2 mRNA expression was shown in glomerular RNA within $30 \mathrm{~min}$ of anti-GBM Ab injection. This elevation in MIP-2 was confirmed at the protein level using Western blot analysis of glomerular lysates. Administration of anti-MIP-2 Ab just before the injection of anti-GBM Ab produced a $40 \%$ decrease in infiltrating neutrophils at $4 \mathrm{~h}$ and a reduction in glomerular injury at $24 \mathrm{~h}$, reflected by a decrease in intraglomerular capillary periodic acid-Schiff-positive accumulations previously shown to be characteristic of fibrin deposits (29). These morphologic changes were associated with a 

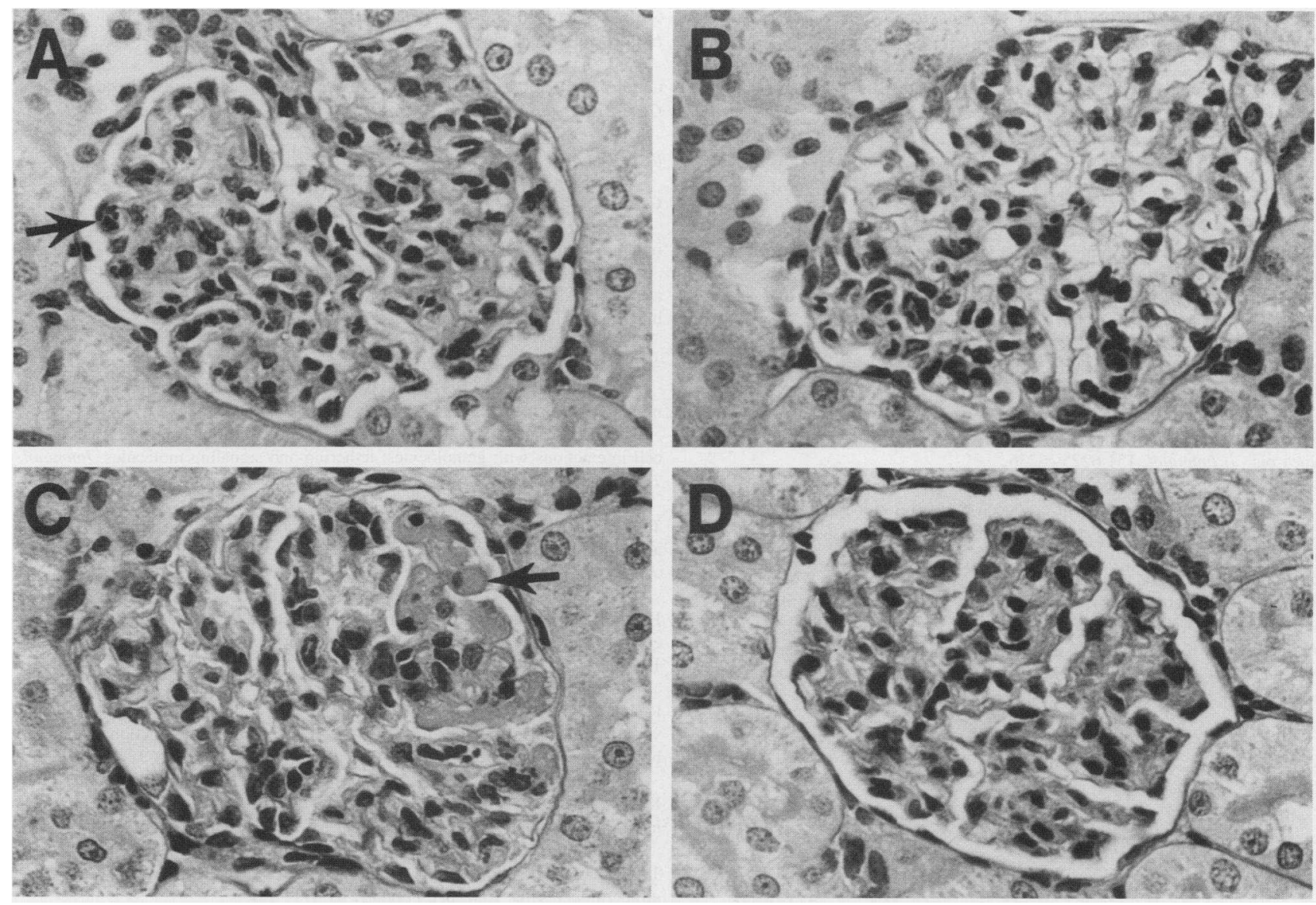

Figure 9. (A) The influx of polymorphonuclear leukocytes (arrow) in the NRS/anti-GBM Ab group (group I) was reduced in the anti-MIP-2/ anti-GBM $\mathrm{Ab}$ group in $B$ (group II). In $C$ (group III), periodic acid-Schiff-positive material corresponding to fibrin-containing deposits (arrow) were also reduced after anti-MIP-2 Ab treatment shown in $D$ (group IV). Periodic acid-Schiff stain; original magnification of 400 .

reduction in urinary protein excretion, confirming the beneficial effect. The effects were related to the action of the anti-MIP$2 \mathrm{Ab}$ on the influx of neutrophils and not to an alteration in the underlying inducing stimulus, since no alterations in binding of anti-GBM Ab binding (paired-label isotope study), complement fixation, or IL-10, TNF $\alpha$, or ICAM-1 expression could be attributed to the anti-MIP-2 Ab administration.

The anti-MIP-2 Ab-associated decrease in MIP-2 mRNA in comparison with the unchanged levels of IL-1, TNF $\alpha$, and ICAM-1 mRNA suggests that the anti-MIP-2 Ab did not activate other mediator mechanisms. The decrease in MIP-2 probably related to the decrease in neutrophils. This is supported by the demonstration of MIP-2 mRNA in neutrophils by RNase protection assay (data not shown). Another interesting possibility is that the MIP-2 may induce its own gene expression, like MGSA/gro (74), and the anti-MIP-2 Ab may block the MIP2 induction amplified by autocrine regulation. Additional studies are needed to confirm these observations. The anti-MIP-2 $\mathrm{Ab}$ effect on neutrophil influx was incomplete and C5a, $\mathrm{LTB}_{4}$, $\mathrm{PAF}$, and $\mathrm{CINC} / \mathrm{KC}$ could contribute to a portion of the residual chemotactic activity involved in neutrophil influx. The existence of additional chemotactic peptides cannot be excluded. For example, in ongoing studies, mRNA expression of another chemotactic protein, $\mathrm{CP}-10$, highly homologous with the $\mathrm{Ca}^{2+}$-binding S100 protein $(75,76)$ has been identified in the same model (in preparation), which may contribute to some neutrophil in- filtration after blocking MIP-2. Further study is needed to examine the role of CP-10 in this model.

\section{Acknowledgments}

This is publication 8692-IMM from the Department of Immunology, The Scripps Research Institute, La Jolla, California 92037. This work was supported in part by U.S. Public Health Service grants DK-20043 and DK-42717. Statistical analysis was done as part of the General Clinical Research Computing Center award (MO1 RR00833).

\section{References}

1. Rot, A. 1992. Endothelial cell binding of NAP-1/IL-8: role in neutrophil emigration. Immunol. Today. 13:291-294.

2. Lasky, L. A. 1992. Selectins: interpreters of cell-specific carbohydrate information during inflammation. Science (Wash. DC). 258:964-969.

3. Bevilacqua, M. P. 1993. Endothelial-leukocyte adhesion molecules. Annual Review of Immunology. 11:767-804.

4. Rosen, S. D. 1993. Cell surface lectins in the immune system. Seminars in Immunology. 5:237-247.

5. Briscoe, D. M., and R. S. Cotran. 1993. Role of leukocyte-endothelial cell adhesion molecules in renal inflammation: in vitro and in vivo studies. Kidney Int. 44 (Suppl. 42):S27-S34. (Published erratum appears in Kidney Int. 44:658, 1993.)

6. Springer, T. A. 1994. Traffic signals for lymphocyte recirculation and leukocyte emigration: the multistep paradigm. Cell. 76:301-314.

7. Lindley, I. J. D., J. Westwick, and S. L. Kunkel. 1993. Nomenclature announcement: the chemokines. Immunol. Today. 14:24.

8. Oppenheim, J. J., C. O. C. Zachariae, N. Mukaida, and K. Matsushima. 
1991. Properties of the novel proinflammatory supergene "intercrine" cytokine family. Annuual Review of Immunology. 9:617-648.

9. Miller, M. D., and M. S. Krangel. 1992. Biology and biochemistry of the chemokines: a family of chemotactic and inflammatory cytokines. Crit. Rev. Immunol. 12:17-46.

10. Tekamp-Olson, P., C. Gallegos, D. Bauer, J. McClain, B. Sherry, M. Fabre, S. van Deventer, and A. Cerami. 1990. Cloning and characterization of cDNAs for murine macrophage inflammatory protein 2 and its human homologues. J. Exp. Med. 172:911-919.

11. Iida, N., and G. R. Grotendorst. 1990. Cloning and sequencing of a new gro transcript from activated human monocytes: expression in leukocytes and wound tissue. Mol. Cell. Biol. 10:5596-5599. (Published erratum appears in Mol. Cell. Biol. 10:6821, 1990.)

12. Haskill, S., A. Peace, J. Morris, S. A. Sporn, A. Anisowicz, S. W. Lee, T. Smith, G. Martin, P. Ralph, and R. Sager. 1990. Identification of three related human GRO genes encoding cytokine functions. Proc. Natl. Acad. Sci. USA. 87:7732-7736.

13. Yoshimura, T., and D. G. Johnson. 1993. cDNA cloning and expression of guinea pig neutrophil attractant protein-1 (NAP-1). NAP-1 is highly conserved in guinea pig. J. Immunol. 151:6225-6236.

14. Watanabe, K., K. Konishi, M. Fujioka, S. Kinoshita, and H. Nakagawa. 1989. The neutrophil chemoattractant produced by the rat kidney epithelioid cell line NRK-52E is a protein related to the $\mathrm{KC} /$ gro protein. J. Biol. Chem. 264:19559-19563.

15. Konishi, K., Y. Takata, M. Yamamoto, K. Yomogida, K. Watanabe, S. Tsurufuji, and M. Fujioka. 1993. Structure of the gene encoding rat neutrophil chemo-attractant Gro. Gene (Amst.). 126:285-286.

16. Saukkonen, K., S. Sande, C. Cioffe, S. Wolpe, B. Sherry, A. Cerami, and E. Tuomanen. 1990. The role of cytokines in the generation of inflammation and tissue damage in experimental gram-positive meningitis. J. Exp. Med. 171:439448 .

17. Appelberg, R. 1992. Macrophage inflammatory proteins MIP-1 and MIP2 are involved in $\mathrm{T}$ cell-mediated neutrophil recruitment. J. Leukocyte Biol. 52:303-306.

18. Huang, S., J. D. Paulauskis, J. J. Godleski, and L. Kobzik. 1992. Expression of macrophage inflammatory protein-2 and $\mathrm{KC} \mathrm{mRNA}$ in pulmonary inflammation. Am. J. Pathol. 141:981-988.

19. Kobzik, L., S. Huang, J. D. Paulauskis, and J. J. Godleski. 1993. Particle opsonization and lung macrophage cytokine response. J. Immunol. 151:27532759.

20. Gubler, U., and B. J. Hoffman. 1983. A simple and very efficient method for generating cDNA libraries. Gene (Amst.). 25:263-269.

21. Short, J. M., J. M. Fernandez, J. A. Sorge, and W. D. Huse. 1988. גZAP: A bacteriophage $\gamma$ expression vector with in vivo excision properties. Nucleic Acids Res. 15:7583-7600.

22. Sanger, R., S. Nicklen, and A. R. Coulson. 1977. DNA sequencing with chain-terminating inhibitors. Proc. Natl. Acad. Sci. USA. 74:5463-5467.

23. Feng, L., Y. Xia, and C. B. Wilson. 1994. Alternative splicing of the NC1 domain of the human $\alpha 3$ (IV) collagen gene. Differential expression of mRNA transcripts that predict three protein variants with distinct carboxyl regions. $J$. Biol. Chem. 269:2342-2348.

24. Feng, L., Y. Xia, J. I. Kreisberg, and C. B. Wilson. 1994. Interleukin-1 $\alpha$ (IL-1) stimulates KC synthesis in rat mesangial cells: glucocorticoids transcriptionally inhibit KC induction by IL-1. Am. J. Physiol. (Renal). 266:F713-F722.

25. Goto, K., S. Nakamura, F. Goto, and M. Yoshinaga. 1984. Generation of an interleukin-1-like lymphocyte-stimulating factor at inflammatory sites: correlation with the infiltration of polymorphonuclear leukocytes. Br. J. Exp. Pathol. 65:521 532.

26. Yoshimura, T., and N. Yuhki. 1991. Neutrophil attractant/activation protein-1 and monocyte chemoattractant protein-1 in rabbit. cDNA cloning and their expression in spleen cells. J. Immunol. 146:3483-3488.

27. Blantz, R. C., and C. B. Wilson. 1976. Acute effects of anti-glomerular basement membrane antibody on the process of glomerular filtration in the rat. J. Clin. Invest. 58:899-911.

28. Wilson, C. B., F. J. Dixon, J. G. Fortner, and G. J. Cerilli. 1971. Glomerular basement membrane-reactive antibody in anti-lymphocyte globulin. J. Clin. Invest. $50: 1525-1535$.

29. Feng, L., W. W. Tang, D. J. Loskutoff, and C. B. Wilson. 1993. Dysfunction of glomerular fibrinolysis in experimental antiglomerular basement membrane antibody glomerulonephritis. J. Am. Soc. Nephrol. 3:1753-1764.

30. Tang, W. W., L. Feng, J. L. Vannice, and C. B. Wilson. 1994. Interleukin1 receptor antagonist ameliorates experimental anti-glomerular basement membrane antibody-associated glomerulonephritis. J. Clin. Invest. 93:273-279.

31. Chomczynski, P., and N. Sacchi. 1987. Single-step method of RNA isolation by acid guanidinium thiocyanate-phenol-chloroform extraction. Anal. Biochem. 162:156-159.

32. Feng, L., W. Sun, Y. Xia, W. W. Tang, P. Chanmugam, E. Soyoola, C. B. Wilson, and D. Hwang. 1993. Cloning two isoforms of rat cyclooxygenase: differential regulation of their expression. Arch. Biochem. Biophys. 307:361-368.
33. Wilcox, J. N. 1993. Fundamental principles of in situ hybridization. $J$. Histochem. Cytochem. 41:1725-1733.

34. Shaw, G., and R. Kamen. 1986. A conserved AU sequence from the 3' untranslated region of GM-CSF mRNA mediates selective mRNA degradation. Cell. 46:659-667.

35. Pober, J. S., and R. S. Cotran. 1990. Cytokines and endothelial cell biology. Physiol. Rev. 70:427-451.

36. Osborn, L. 1990. Leukocyte adhesion to endothelium in inflammation. Cell. 62:3-6.

37. Cotran, R. S., and J. S. Pober. 1990. Cytokine-endothelial interactions in inflammation, immunity, and vascular injury. J. Am. Soc. Nephrol. 1:225-235.

38. Lawrence, M. B., and T. A. Springer. 1991. Leukocytes roll on a selectin at physiologic flow rates: distinction from and prerequisite for adhesion through integrins. Cell. 65:859-873.

39. Albelda, S. M. 1991. Endothelial and epithelial cell adhesion molecules. Am. J. Respir. Cell Mol. Biol. 4:195-203.

40. Butcher, E. C. 1991. Leukocyte-endothelial cell recognition: three (or more) steps to specificity and diversity. Cell. 67:1033-1036.

41. Zimmerman, G. A., S. M. Prescott, and T. M. McIntyre. 1992. Endothelial cell interactions with granulocytes: tethering and signaling molecules. Immunol. Today. 13:93-100.

42. Brady, H. R., O. Spertini, W. Jimenez, B. M. Brenner, P. A. Marsden, and T. F. Tedder. 1992. Neutrophils, monocytes, and lymphocytes bind to cytokineactivated kidney glomerular endothelial cells through L-selectin (LAM-1) in vitro. J. Immunol. 149:2437-2444.

43. Denton, M. D., P. A. Marsden, F. W. Luscinskas, B. M. Brenner, and H. R. Brady. 1991. Cytokine-induced phagocyte adhesion to human mesangial cells: role of CD11/CD18 integrins and ICAM-1. Am. J. Physiol. 261:F1071F1079.

44. Garner, C. M., G. M. Richards, D. Adu, A. A. Pall, C. M. Taylor, N. T. Richards, and J. Michael. 1994. Intercellular adhesion molecule-1 (ICAM-1) and vascular cell adhesion molecule-1 (VCAM-1) expression and function on cultured human glomerular epithelial cells. Clin. Exp. Immunol. 95:322-326.

45. Wuthrich, R. P., A. M. Jevnikar, F. Takei, L. H. Glimcher, and V. E Kelley. 1990. Intercellular adhesion molecule-1 (ICAM-1) expression is upregulated in autoimmune murine lupus nephritis. Am. J. Pathol. 136:441-450.

46. Lhotta, K., H. P. Neumayer, M. Joannidis, D. Geissler, and P. König. 1991. Renal expression of intercellular adhesion molecule-1 in different forms of glomerulonephritis. Clin. Sci. (Lond.). 81:477-481.

47. Müller, G. A., J. Markovic-Lipkovski, and C. A. Müller. 1991. Intercellular adhesion molecule-1 expression in human kidneys with glomerulonephritis. Clin. Nephrol. 36:203-208.

48. Waldherr, R., M. Eberlein-Gonska, I. L. Noronha, K. Andrassy, and E. Ritz. 1991. TNF- $\alpha$ and ICAM-1 expression in renal disease. J. Am. Soc. Nephrol. 1:544.

49. Chow, J., R. B. Hartley, C. Jagger, and S. A. Dilly. 1992. ICAM-1 expression in renal disease. J. Clin. Pathol. 45:880-884.

50. Mulligan, M. S., K. J. Johnson, C. W. Smith, D. C. Anderson, and P. A. Ward. 1991. Nephrotoxic nephritis: role of TNF $\alpha$ and adhesion molecules. J. Am. Soc. Nephrol. 2:555.

51. Mulligan, M. S., K. J. Johnson, R. F. Todd III, T. B. Issekutz, M. Miyasaka, T. Tamatani, C. W. Smith, D. C. Anderson, and P. A. Ward. 1993. Requirements for leukocyte adhesion molecules in nephrotoxic nephritis. J. Clin. Invest. 91:577587.

52. Kawasaki, K., E. Yaoita, T. Yamamoto, T. Tamatani, M. Miyasaka, and I. Kihara. 1993. Antibodies against intercellular adhesion molecule-1 and lymphocyte function-associated antigen-1 prevent glomerular injury in rat experimental crescentic glomerulonephritis. J. Immunol. 150:1074-1083.

53. Nishikawa, K., Y. J. Guo, M. Miyasaka, T. Tamatani, A. B. Collins, M. S. Sy, R. T. McCluskey, and G. Andres. 1993. Antibodies to intercellular adhesion molecule $1 /$ lymphocyte function-associated antigen 1 prevent crescent formation in rat autoimmune glomerulonephritis. J. Exp. Med. 177:667-677.

54. Huber, A. R., S. L. Kunkel, R. F. Todd III, and S. J. Weiss. 1991 Regulation of transendothelial neutrophil migration by endogenous interleukin-8. Science (Wash. DC). 254:99-102. (Published erratum appears in Science (Wash. DC). 254:631, 1991.)

55. Brady, H. R., M. D. Denton, W. Jimenez, S. Takata, D. Palliser, and B. M. Brenner. 1992. Chemoattractants provoke monocyte adhesion to human mesangial cells and mesangial cell injury. Kidney Int. 42:480-487.

56. Gómez-Chiarri, M., A. Ortiz, D. Seron, E. Gonzalez, and J. Egido. 1993. The intercrine superfamily and renal disease. Kidney Int. 43(Suppl.39):S-81-S85.

57. Yoshioka, K., T. Takemura, K. Murakami, M. Okada, K. Yagi, H. Miyazato, K. Matsushima, and S. Maki. 1993. In situ expression of cytokines in IgA nephritis. Kidney Int. 44:825-833.

58. Brown, Z., R. M. Strieter, S. W. Chensue, M. Ceska, I. Lindley, G. H. Neild, S. L. Kunkel, and J. Westwick. 1991. Cytokine-activated human mesangial cells generate the neutrophil chemoattractant, interleukin 8. Kidney Int. 40:8690.

59. Kusner, D. J., E. L. Luebbers, R. J. Nowinski, M. Konieczkowski, C. H. 
King, and J. R. Sedor. 1991. Cytokine- and LPS-induced synthesis of interleukin8 from human mesangial cells. Kidney Int. 39:1240-1248.

60. Abbott, F., J. J. Ryan, M. Ceska, K. Matsushima, C. E. Sarraf, and A. J. Rees. 1991. Interleukin- $\beta$ stimulates human mesangial cells to synthesize and release interleukins-6 and -8. Kidney Int. 40:597-605.

61. Zoja, C., J. M. Wang, S. Bettoni, M. Sironi, D. Renzi, F. Chiaffarino, H. E. Abboud, J. Van Damme, A. Mantovani, G. Remuzzi, and A. Rambaldi. 1991. Interleukin- $1 \beta$ and tumor necrosis factor- $\alpha$ induce gene expression and production of leukocyte chemotactic factors, colony-stimulating factors, and interleukin-6 in human mesangial cells. Am. J. Pathol. 138:991-1003.

62. Schmouder, R. L., R. M. Strieter, R. C. Wiggins, S. W. Chensue, and S. L. Kunkel. 1992. In vitro and in vivo interleukin-8 production in human renal cortical epithelia. Kidney Int. 41:191-198.

63. Hechtman, D. H., M. I. Cybulsky, H. J. Fuchs, J. B. Baker, and M. A. Gimbrone, Jr. 1991. Intravascular IL-8. Inhibitor of polymorphonuclear leukocyte accumulation at sites of acute inflammation. J. Immunol. 147:883-892.

64. Hora, K., J. A. Satriano, A. Santiago, T. Mori, E. R. Stanley, Z. Shan, and D. Schlondorff. 1992. Receptors for IgG complexes activate synthesis of monocyte chemoattractant peptide 1 and colony-stimulating factor 1. Proc. Natl. Acad. Sci. USA. 89:1745-1749.

65. Rovin, B. H., T. Yoshiumura, and L. Tan. 1992. Cytokine-induced production of monocyte chemoattractant protein-1 by cultured human mesangial cells. J. Immunol. 148:2148-2153.

66. Stahl, R. A., F. Thaiss, M. Disser, U. Helmchen, K. Hora, and D. Schlondorff. 1993. Increased expression of monocyte chemoattractant protein-1 in antithymocyte antibody-induced glomerulonephritis. Kidney Int. 44:1036-1047.

67. Satriano, J. A., K. Hora, Z. Shan, E. R. Stanley, T. Mori, and D. Schlondorff. 1993. Regulation of monocyte chemoattractant protein-1 and macrophage colony-stimulating factor-1 by IFN-gamma, tumor necrosis factor-alpha, IgG aggregates, and cAMP in mouse mesangial cells. J. Immunol. 150:1971-1978.
68. Grandaliano, G., A. J. Valente, M. M. Rozek, and H. E. Abboud. 1994. Gamma interferon stimulates monocyte chemotactic protein (MCP-1) in human mesangial cells. J. Lab. Clin. Med. 123:282-289.

69. Gomez-Chiarri, M., T. A. Hamilton, J. Egido, and S. N. Emancipator 1993. Expression of IP-10, a lipopolysaccharide- and interferon-gamma-inducible protein, in murine mesangial cells in culture. Am. J. Pathol. 142:433-439.

70. Heeger, P., G. Wolf, C. Meyers, M. J. Sun, S. C. O'Farrell, A. M. Krensky, and E. G. Neilson. 1992. Isolation and characterization of cDNA from renal tubular epithelium encoding murine Rantes. Kidney Int. 41:220-225.

71. Wolf, G., S. Aberle, F. Thaiss, P. J. Nelson, A. M. Krensky, E. G. Neilson, and R. A. Stahl. 1993. TNF alpha induces expression of the chemoattractant cytokine RANTES in cultured mouse mesangial cells. Kidney Int. 44:795-804

72. Brown, Z., R. M. Strieter, G. H. Neild, R. C. Thompson, S. L. Kunkel, and J. Westwick. 1992. IL-1 receptor antagonist inhibits monocyte chemotactic peptide 1 generation by human mesangial cells. Kidney Int. 42:95-101.

73. Wu, X., A. J. Wittwer, L. S. Carr, B. A. Crippes, J. E. DeLarco, and J. B. Lef kowith. 1994. Cytokine-induced neutrophil chemoattractant mediates neutrophil influx in immune complex glomerulonephritis in rat. J. Clin. Invest. 94:337-344.

74. Wen, D. Z., A. Rowland, and R. Derynck. 1989. Expression and secretion of gro/MGSA by stimulated human endothelial cells. EMBO (Eur. Mol. Biol. Organ.) J. 8:1761-1766.

75. Lackmann, M., C. J. Cornish, R. J. Simpson, R. L. Moritz, and C. L. Geczy. 1992. Purification and structural analysis of a murine chemotactic cytokine (CP-10) with sequence homology to S100 proteins. J. Biol. Chem. 267:74997504

76. Devery, J. M., N. J. King, and C. L. Geczy. 1994. Acute inflammatory activity of the S100 protein CP-10. Activation of neutrophils in vivo and in vitro. J. Immunol. 152:1888-1897. 